Open Access

\title{
Decline in objective physical activity over a 10 -year period in a Japanese elementary school
}

\author{
Aya Itoi ${ }^{1}$, Yosuke Yamada ${ }^{2}$, Satoshi Nakae ${ }^{2}$ and Misaka Kimura ${ }^{3,4^{*}}$
}

\begin{abstract}
Background: The purpose of this study was to examine the change in accelerometer-derived daily physical activity (PA) and activity record-derived daily activities over a 10-year period in urban elementary schoolchildren in Japan.

Methods: A total of 233 sixth-grade children (11-12 years old) in a same elementary school in Kyoto participated in the study ( $n=125$ and 108 in 1999 and 2009, respectively). The participant rate is 91.9 and $98.2 \%$ in 1999 and 2009, respectively. The size and shape of the school district was not changed. The children were instructed to wear an accelerometer for 5 consecutive days of weekday and to keep minute-by-minute 24-h activity records with the assistance of their parents. The school-day scheduling was similar between 1999 and 2009 ( 29 and 27 sessions of 45-min class per week, respectively).

Results: From 1999 to 2009, step counts considerably decreased (20,832 vs. 12,237 steps per day in boys and 16,087 vs. 10,748 steps per day in girls; $P<0.001)$ with concomitant significant decreases in total energy expenditure $(P=0.011)$, activity energy expenditure $(P<0.001)$, and physical activity level $(P<0.001)$. Time spent playing outdoors and walking to school were also significantly less in 2009 than $1999(P<0.001)$. Accelerometer-measured PA was significantly associated with the amount of time spent playing outdoors and walking to school.
\end{abstract}

Conclusions: These results indicate that elementary schoolchildren in 2009 spend less time playing outdoors and walking to school, perform less PA, and take fewer steps than children of a decade ago.

Keywords: Schoolchildren, Accelerometer, Step counts, Playing outdoors, Walking to school

\section{Background}

There is an indirect evidence of a recent and considerable decrease in physical activity (PA) in schoolchildren. In the late 1990s, Rowlands et al. [1] reported that boys and girls in 8-10 years old from local primary school in Bangor, North Wales, averaged $16,035 \pm 5999$ and $12,729 \pm 4026$ steps per day $(P<0.05)$, respectively. In contrast, in 2007, McCormack et al. [2] found that a similar population of boys and girls in grades 5-7 attending public elementary schools in Perth, Western

\footnotetext{
* Correspondence: misaka@kyotogakuen.ac.jp

${ }^{3}$ Department of Bioscience and Biotechnology, Faculty of Bio-environmental Science, Kyoto Gakuen University, 1-1, Nanjo-Otani, Sogabe, Kameoka, Kyoto 621-8555, Japan

${ }^{4}$ Laboratory of Sports and Health Science, Kyoto Prefectural University of Medicine, 465 Kajii-cho, Kamigyo-ku, Kyoto 602-0841, Japan

Full list of author information is available at the end of the article
}

Australia, took $12,270 \pm 3350$ and $10,681 \pm 2745$ steps per day $(P<0.001)$, respectively. Likewise, in Japan, Kito et al. [3] reported in the early 1980s that boys and girls in 9-11 years old in Aich Prefecture took 18,812 and 14,048 steps per day, respectively, while Nemoto et al. [4] found that boys and girls in fourth-graders located in mountain area in Yamanashi Prefecture took $14,875 \pm 4339$ and $11,155 \pm 2033$ steps per day $(P<0.001)$ in 2009. Although not directly comparable, these results suggest that childhood PA might decrease over the past few decades; however, it must be noted that these separately conducted studies examined schoolchildren from different regions and populations and used different step counters, and thus they cannot be directly compared.

This is particularly true because previous studies have indicated that PA and step counts are regionally variable, even within the same country [5-7]. Itoi et al. [5]

\section{Biomed Central}


reported that the overweight and obesity prevalence in Japan was significantly higher in rural regions than in urban regions. The number of steps per day, activity energy expenditure (AEE), physical activity level (PAL), and duration of walking to school were significantly lower in rural children than in urban children. The PA and duration of the walk to school were significantly correlated with body mass index (BMI). Joens-Matre et al. [6] examined BMI and questionnaire-derived PA of fourth- to sixth-grade children in Iowa, USA. The prevalence of being overweight was higher, and PA was lower among rural children compared with urban children. Bassett et al. [7] found that Old Order Amish youth had high daily physical activity levels, as measured by a step counter and that obesity prevalence was quite low. Onywera et al. [8] reported that rural Kenyan children were more physically active than their urban counterparts, with a mean average steps per day $( \pm$ SE) of $14,700 \pm 521$ and $11,717 \pm 561 \quad(P<0.001)$ for rural and urban children, respectively. In addition, significantly different outputs are observed with different types of step counters or accelerometers. Studies are needed in which daily PA and step counts are measured using the same accelerometer in the same region over a long time period in order to reliably examine changes in the PA and lifestyle in schoolchildren.

Uechi et al. [9] examined the effect of playing outdoors during break between classes on daily PA in 9-12 years children and found that the children playing outdoors during breaks between classes had significantly higher total step counts $(12,118 \pm 3442$ steps $)$ compared with the children who did not play outdoors $(9265 \pm 2976$ steps, $P<0.001)$. We previously compared urban and rural sixth-grade schoolchildren in Japan and found that rural children were less physically active because fewer of them walked to school owing to the prevalence of commuting by car [5]. Therefore, we hypothesized that the decline in PA in recent children relative to 1 decade ago was at least partly associated with decreases in time spent playing outdoors and walking to school.

The purpose of this study was to compare the daily PA levels of schoolchildren today with those of children 1 decade ago in a Japanese school located in Kyoto. We hypothesized (1) that the PA level would be lower at recent than 1 decade ago and (2) that lower daily PA levels would be associated with less time spent playing outdoors and walking to school.

\section{Methods}

\section{Participants}

A total of 233 sixth-grade children (11-12 years old) in an urban public elementary school in Kyoto, Japan, participated in the study. Sixty-two boys and 63 girls participated in 1999, and 56 boys and 52 girls participated in
2009. The data came from the same school in 1999 and 2009. In 1999, 136 sixth-grade children had been enrolled in the school, and we collected PA data from $91.9 \%$ of children $(n=125)$. In 2009, 110 sixth-grade children had been enrolled in the school, and we collected PA data from $98.2 \%$ of children $(n=108)$. Informed consent was obtained from all participating children, as well as their parents and teachers. The study was approved by the Ethics Committee of the Kyoto Prefectural University of Medicine (Reference number: RBMR-C-588).

Kyoto is one of the ten major cities in Japan; it has a population of over 1.47 million and a population density of 1780 people per $\mathrm{km}^{2}$. The size and shape of the school district were not changed between the two time points. Kyoto is one of the most historic cities in Japan, and this school locates one historical area. Because of preservation of historical areas, the rate of moving in the school district tends to lower than other urban cites. For socioeconomic status (SES), the number of vehicles owned $(-11.3 \%)$, appraised value of land $(-21.8 \%)$, and family income $(-6.6 \%)$ decreased in the 10 years in Kyoto city, which is similar to countrywide trend. Landscape between 1999 and 2009 in the school district was not much different. The school-day scheduling was also similar between 1999 and 2009 (29 and 27 sessions of 45-min class per week, respectively).

\section{Anthropometric characteristics}

The age, grade, sex, and physical characteristics of the children were assessed. All measurements were conducted during the fall season. Body mass $(\mathrm{kg})$ and height $(\mathrm{cm})$ were measured to the nearest $0.1 \mathrm{~kg}$ and $0.1 \mathrm{~cm}$, respectively, using a professional physician's scale and stadiometer with the children standing barefoot and wearing one layer of light clothing. The BMI $\left(\mathrm{kg} \cdot \mathrm{m}^{-2}\right)$ of each child was calculated as their body mass $(\mathrm{kg})$ divided by their height squared $\left(\mathrm{m}^{2}\right)$. Children were classified as overweight (OW) or obese (OB) according to the international definitions for childhood obesity that were developed in a workshop organized by the International Obesity Task Force (IOTF) [10]. IOTF cut off points for BMI for overweight and obesity by sex between 2 and 18 years was defined to pass through body mass index of 25 and $30 \mathrm{~kg} \cdot \mathrm{m}^{-2}$ at age 18 , obtained by averaging data from Brazil, Great Britain, Hong Kong, the Netherlands, Singapore, and USA. For example, the corresponded BMI of OW is $\geq 20.55$ in boys and $\geq 20.74$ in girls, and that of $\mathrm{OB}$ is $\geq 25.10$ in boys and $\geq 25.42$ in girls for 11 years old.

\section{Accelerometer}

A detailed description of the accelerometer used in this study has been provided elsewhere [5, 11-13]. A uniaxial 
pedometer/accelerometer (Kenz Lifecorder/Calorie counter; Kenz, Suzuken Co. Ltd., Nagoya, Japan) was continuously and rigidly attached to the waistband of each participating child during all waking hours for 5 consecutive days of weekdays, excluding time spent bathing or in water. The accelerometer is one of the most reliable pedometer/accelerometers for step counts [11, 14-16]. Japanese Industrial Standards Committee established a pedometer/accelerometer standard in 1993 (JIS S7200-1993; president of the committee, Dr. Yoshiro Hatano) and instructs to test pedometers with acceleration of 2.4 and $4.9 \mathrm{~m} / \mathrm{s}^{2}$ induced by the oscillation generator with maximum acceptable error of $\pm 3 \%$. The pedometer/accelerometers were checked and validated using the same Japanese Industrial Standards (JIS) method by the company before each survey in 1999 and 2009. The participants were asked to record all times and dates that they did not wear the accelerometer. The records and accelerometer data were checked, and the children were interviewed if a lack of compliance was suspected. The accelerometer data was accepted wearing of $10 \mathrm{~h}$ a day and 3 days above [17]. This accelerometer has been previously validated against both indirect calorimetry and the doubly labeled water method in adults and children $[5,11,13,18]$. The reported margin of error in the number of steps recorded is less than $3 \%[15,16,19]$. Additionally, this accelerometer has superior step counting accuracy under both controlled [16, 20] and free-living conditions [15] in comparison with other instruments [21]. Although the total (TEE) and physical activity energy expenditure (AEE), and physical activity level (PAL) estimated by the accelerometer is highly correlated with the values obtained by the doubly labeled water method, the accelerometer underestimates TEE, AEE, and PAL $[5,13]$. Thus, we adjusted these values using a correction factor validated in previous experiments [5]. Accelerometer data from eight children were excluded from analysis because of extremely low step counts due to long non-wear periods.

\section{4-h activity records}

Five-day minute-by-minute activity records were used to assess PA levels as described previously [5, 22]. Participants used a form specially designed to facilitate diary maintenance to record each activity minute-by-minute. They were instructed to record when their activity changed by drawing a line at the end of one activity under the corresponding time. A detailed demonstration and an example of a completed sample were given to the teachers, parents, and children before they began recording. We asked the teachers and parents to assist the children in completing their activity records. All activity records were checked, and any missing information was obtained. The participants were requested to continue with and record all of their regular daily activities. The activity record data from 17 children were excluded from analysis because records were missing, or the child had given up recording.

\section{Statistical analysis}

Normal distribution was tested using a KolmogorovSmirnov test. Height, PAL, and duration of walking to school, watching TV, and sleeping, and bedtime showed normal distribution statistically. Two-way ANOVA was used with year (1999 or 2009) and sex (boy or girl) as between-subject factors for these variables. The other data of the variables showed no normal distribution. Mann-Whitney test was used to identify the effects of year and sex for these variables. Results are given as means, standard deviation (SD), median, and 5th and 95th percentiles of the variables. Differences in the distribution of weight status were examined using the chi-square test. The relationship between accelerometermeasured PA and duration of specific activities and between BMI and PA or duration of specific activities were examined using the Spearman rank correlation analysis. Significance was set at $P<0.05$. Statistical analyses were conducted using SPSS statistics (Windows Version 22; SPSS Inc., Chicago, Illinois).

\section{Results}

Table 1 shows the mean, SD, median, and 5th and 95th percentiles values for the variables with normal distribution. Table 2 shows the means, SD, median, and 5th and 95th percentiles values for the variables with nonnormal distribution. The prevalence of obesity by IOTF is shown in Table 3.

\section{Physical characteristics}

Height $\left(F_{(229,1)}=7.896, P=0.005\right)$, weight $(U=8295$, $P=0.003)$, and BMI $(U=7905, P=0.024)$ were significantly higher in 2009 than in 1999. Slightly, more children were classified as overweight or obese in 2009 compared with 1999, but this difference did not reach statistical significance $(P>0.05)$.

\section{Accelerometers output}

In 2009, the children took fewer steps $(U=1473, P<0.001)$ and had lower TEE $(U=5009, P=0.011)$, AEE $(U=1100$, $P<0.001)$, and PAL $\left(F_{(221,1)}=69.4, P<0.001\right)$ than the children in 1999. Girls had lower step counts $(U=4320$, $P<0.001)$, TEE $(U=5102, P=0.012)$, AEE $(U=4834$, $P=0.002)$, and PAL $\left(F_{(221,1)}=2.818, P=0.095\right)$ than boys. Significant year and sex interactions were observed in PAL $\left(F_{(221,1)}=4.025, P=0.046\right)$, and the secular decline is greater for boys, compared to girls. 
Table 1 The variables showed normal distribution in Japanese schoolchildren in 1999 and 2009 ( $n=233)$

\begin{tabular}{|c|c|c|c|c|c|c|c|c|c|c|c|c|c|c|c|c|c|c|c|c|}
\hline & \multicolumn{9}{|c|}{1999} & \multicolumn{8}{|l|}{2009} & \multirow{2}{*}{\multicolumn{3}{|c|}{$\begin{array}{l}P \text { value of two-way } \\
\text { ANOVA }\end{array}$}} \\
\hline & \multicolumn{5}{|l|}{ Boys } & \multicolumn{4}{|l|}{ Girls } & \multicolumn{4}{|l|}{ Boys } & \multicolumn{4}{|l|}{ Girls } & & & \\
\hline & & Mean & (SD) & Median & $\begin{array}{l}\text { (5th and 95th } \\
\text { percentiles) }\end{array}$ & Mean & (SD) & Median & $\begin{array}{l}\text { (5th and 95th } \\
\text { percentiles) }\end{array}$ & Mean & (SD) & Median & $\begin{array}{l}\text { (5th and 95th } \\
\text { percentiles) }\end{array}$ & Mean & (SD) & Median & $\begin{array}{l}\text { (5th and 95th } \\
\text { percentiles) }\end{array}$ & \multirow[t]{2}{*}{ Year } & \multirow[t]{2}{*}{ Sex } & \multirow[t]{2}{*}{$Y \times S$} \\
\hline & \multicolumn{5}{|c|}{$n=62$} & \multicolumn{4}{|l|}{$n=63$} & \multicolumn{4}{|l|}{$n=56$} & \multicolumn{4}{|l|}{$n=52$} & & & \\
\hline \multicolumn{21}{|c|}{ Physical characteristics } \\
\hline Height & $\mathrm{cm}$ & 145.8 & $(6.5)$ & 145.1 & $(136.5-157.5)$ & 147.1 & $(6.6)$ & 148.0 & $(135.1-157.1)$ & 147.8 & (7.6) & 148.4 & $(134.6-161.5)$ & 150.1 & $(6.0)$ & 149.8 & $(141.6-160.5)$ & 0.005 & 0.044 & 0.615 \\
\hline \multicolumn{21}{|c|}{ Accelerometer output } \\
\hline PAL & & 1.92 & $(0.16)$ & 1.89 & $(1.71-2.16)$ & 1.85 & $(0.20)$ & 1.83 & $(1.64-2.11)$ & 1.72 & $(0.08)$ & 1.72 & $(1.57-1.86)$ & 1.73 & $(0.08)$ & 1.73 & $(1.61-1.85)$ & $<0.001$ & 0.095 & 0.046 \\
\hline \multicolumn{21}{|c|}{ Time spent performing specific activities } \\
\hline $\begin{array}{l}\text { Walking to } \\
\text { school }\end{array}$ & $\min$ & 41 & (24) & 38 & $(9-93)$ & 46 & (27) & 40 & $(5-98)$ & 35 & (20) & 34 & $(5-70)$ & 39 & (22) & 40 & $(8-73)$ & 0.043 & 0.202 & 0.954 \\
\hline TV Watching & $\min$ & 108 & (61) & 105 & $(13-229)$ & 98 & (61) & 96 & $(3-211)$ & 90 & (57) & 84 & $(1-198)$ & 111 & (84) & 92 & $(8-254)$ & 0.775 & 0.549 & 0.088 \\
\hline Sleeping & $\min$ & 515 & (48) & 523 & $(427-583)$ & 502 & $(42)$ & 510 & $(427-570)$ & 500 & (41) & 503 & $(421-568)$ & 490 & (50) & 498 & $(392-574)$ & 0.029 & 0.069 & 0.790 \\
\hline Bedtime & $h: m$ & $22: 30$ & $\left(51^{\prime}\right)$ & $22: 20$ & (21:00-00:01) & $22: 42$ & $\left(44^{\prime}\right)$ & $22: 43$ & (21:28-00:00) & $22: 36$ & $\left(42^{\prime}\right)$ & $22: 28$ & $(21: 37-23: 36)$ & $22: 47$ & $\left(51^{\prime}\right)$ & $22: 48$ & (21:18-00:17) & 0.435 & 0.070 & 0.985 \\
\hline
\end{tabular}

PAL physical activity level; Significance was set at $\mathrm{P}<0.05$ 
Table 2 The variables showed no normal distribution in Japanese schoolchildren in 1999 and 2009 ( $n=233$ )

\begin{tabular}{|c|c|c|c|c|c|c|c|c|c|c|c|c|c|c|c|c|c|c|c|}
\hline & & \multicolumn{8}{|l|}{1999} & \multicolumn{8}{|l|}{2009} & \multirow{2}{*}{\multicolumn{2}{|c|}{$\begin{array}{l}\text { Mann-Whitney } \\
\text { Test }\end{array}$}} \\
\hline & & \multicolumn{4}{|l|}{ Boys } & \multicolumn{4}{|l|}{ Girls } & \multicolumn{4}{|l|}{ Boys } & \multicolumn{4}{|l|}{ Girls } & & \\
\hline & & Mean & (SD) & Median & $\begin{array}{l}\text { (5th and 95th } \\
\text { percentiles) }\end{array}$ & Mean & (SD) & Median & $\begin{array}{l}\text { (5th and 95th } \\
\text { percentiles) }\end{array}$ & Mean & (SD) & Median & $\begin{array}{l}\text { (5th and 95th } \\
\text { percentiles) }\end{array}$ & Mean & (SD) & Median & $\begin{array}{l}\text { (5th and 95th } \\
\text { percentiles) }\end{array}$ & \multirow[t]{2}{*}{ Year } & \multirow[t]{2}{*}{ Sex } \\
\hline & & \multicolumn{4}{|l|}{$n=62$} & \multicolumn{4}{|l|}{$n=63$} & \multicolumn{4}{|l|}{$n=56$} & \multicolumn{4}{|l|}{$n=52$} & & \\
\hline \multicolumn{20}{|c|}{ Physical characteristics } \\
\hline Weight & $\mathrm{kg}$ & 37.1 & (6.3) & 35.9 & $(29.1-51.5)$ & 38.5 & $(6.7)$ & 38.2 & $(28.8-53.0)$ & 39.6 & $(8.3)$ & 39.5 & $(27.5-57.4)$ & 41.7 & (7.4) & 40.9 & $(31.4-57.3)$ & 0.003 & 0.042 \\
\hline BMI & $\mathrm{kg} \cdot \mathrm{m}^{-2}$ & 17.4 & (2.3) & 16.7 & $(14.7-22.0)$ & 17.7 & (2.3) & 17.4 & $(14.2-22.4)$ & 18.0 & (2.6) & 17.8 & $(14.0-23.9)$ & 18.5 & (2.5) & 18.3 & $(15.2-23.8)$ & 0.024 & 0.125 \\
\hline \multicolumn{20}{|c|}{ Accelerometer output } \\
\hline $\begin{array}{l}\text { Step } \\
\text { count }\end{array}$ & step & 20,832 & $(4694)$ & 20,748 & $(14,277-30,806)$ & 16,087 & (4840) & 15,720 & $(8336-25,330)$ & 12,237 & (2934) & 12,014 & $(7492-18,324)$ & 10,748 & $(2668)$ & 11,226 & $(6278-14,824)$ & $<0.001$ & $<0.001$ \\
\hline TEE & kcal & 2512 & (381) & 2434 & (1977-3258) & 2318 & (398) & 2268 & (1652-3065) & 2303 & (383) & 2337 & $(1677-3036)$ & 2245 & (285) & 2234 & (1765-2790) & 0.011 & 0.012 \\
\hline AEE & kcal & 805 & (247) & 744 & (463-1309) & 626 & (213) & 592 & $(332-1056)$ & 408 & (118) & 408 & $(214-648)$ & 367 & $(100)$ & 391 & $(202-537)$ & $<0.001$ & 0.002 \\
\hline \multicolumn{20}{|c|}{ Time spent performing specific activities } \\
\hline $\begin{array}{l}\text { Playing } \\
\text { outdoor }\end{array}$ & $\min$ & 46 & (36) & 42 & $(0-114)$ & 31 & (29) & 25 & $(0-81)$ & 31 & (33) & 17 & $(0-109)$ & 13 & (14) & 11 & $(0-47)$ & $<0.001$ & 0.002 \\
\hline $\begin{array}{l}\text { Club } \\
\text { activity }\end{array}$ & $\min$ & 26 & (43) & 16 & $(0-86)$ & 28 & (36) & 13 & $(0-91)$ & 28 & (22) & 25 & $(0-85)$ & 15 & (17) & 16 & $(0-59)$ & 0.473 & 0.086 \\
\hline $\begin{array}{l}\text { Video } \\
\text { game }\end{array}$ & $\min$ & 29 & (40) & 13 & $(0-123)$ & 8 & (19) & 0 & $(0-45)$ & 29 & (34) & 22 & $(0-104)$ & 24 & (55) & 6 & $(0-93)$ & 0.011 & $<0.001$ \\
\hline Hobby & $\min$ & 13 & (19) & 5 & $(0-52)$ & 17 & (18) & 13 & $(0-60)$ & 9 & (16) & 2 & $(0-39)$ & 20 & (24) & 12 & $(0-77)$ & 0.406 & 0.001 \\
\hline Studying & $\min$ & 62 & (75) & 39 & (3-276) & 66 & (79) & 36 & (0-288) & 46 & (37) & 38 & $(0-121)$ & 46 & (34) & 36 & $(7-125)$ & 0.606 & 0.884 \\
\hline $\begin{array}{l}\text { Awake } \\
\text { time }\end{array}$ & $h: m$ & 7:02 & $\left(20^{\prime}\right)$ & 7:00 & $(6: 30-7: 40)$ & 7:04 & $\left(27^{\prime}\right)$ & 7:09 & $(5: 59-7: 44)$ & $6: 56$ & $\left(30^{\prime}\right)$ & 7:01 & $(5: 54-7: 42)$ & $6: 58$ & $\left(31^{\prime}\right)$ & 7:01 & $(6: 00-7: 37)$ & 0.195 & 0.253 \\
\hline
\end{tabular}

BMI body mass index, TEE total energy expenditure, AEE activity energy expenditure; Significance was set at $\mathrm{P}<0.05$ 
Table 3 The prevalence of obesity by IOTF criteria obesity

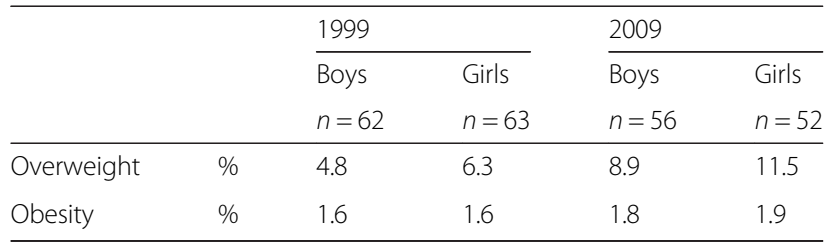

IOTF International Obesity Task Force

\section{Time spent performing specific activities}

In 2009, the children spent less time playing outdoors $(U=3930, P<0.001)$ and walking to school $\left(F_{(191,1)}=\right.$ 4.159, $P=0.043)$ than in 1999 . The duration of sleeping $\left(F_{(212,1)}=4.828, P=0.029\right)$ was also significantly less in 2009 than in 1999. The duration of video games $(U=6926, P=0.011)$ was significantly longer in 2009 than in 1999. No significant interactions between year and sex were observed for any of the variables (Tables 1,2 , and 3 ).

Time spent playing outdoors was significantly correlated with accelerometer-measured PA in 1999 (for step count, $\rho=0.300, P=0.001$; TEE, $\rho=0.243, P=0.010$; AEE, $\rho=0.295, P=0.002$; PAL, $\rho=0.432, P<0.001)$. Time spent playing outdoors was significantly correlated with accelerometer-measured PA also in 2009 (for step count, $\rho=0.413, P<0.001$; AEE, $\rho=0.360$, $P<0.001 ;$ PAL, $\rho=0.309, \quad P=0.002)$. Time spent playing outdoors was significantly correlated with accelerometer-measured PA in boy (for step count, $\rho=0.293, P=0.003$; TEE, $\rho=0.271, P=0.006$; AEE, $\rho=$ 0.346, $P<0.001$; PAL, $\rho=0.410, P<0.001)$. Time spent playing outdoors was significantly correlated with accelerometer-measured PA in girl as well (for step count, $\rho=0.427, P<0.001 ; \mathrm{AEE}, \rho=0.424, P<0.001$; PAL, $\rho=0.438, \quad P<0.001)$. Time spent walking to school was not significantly correlated with accelerometermeasured PA in 1999, but was significantly correlated with accelerometer-measured PA in 2009 (for step count, $\rho=0.451, P<0.001$; AEE, $\rho=0.290, P=0.005$; PAL, $\rho=0.363, \quad P<0.001)$. Time spent walking to school was significantly correlated with accelerometermeasured PA in boy (for step count, $\rho=0.277, P=0.007$ ). Time spent walking to school was significantly correlated with accelerometer-measured PA in girl as well (for step count, $\rho=0.309, P=0.002$; PAL, $\rho=0.262, P=0.011)$. BMI was significantly and negatively correlated with step counts $(\rho=-0.281, P<0.001)$, duration of sleeping $(\rho=-0.162, P=0.017)$, and positively correlated with bedtime $(\rho=0.167, P=0.014)$.

\section{Discussion}

Our results clearly show that children in a Japanese elementary school had lower step counts $(P<0.001)$, TEE $(P=0.011)$, AEE, $(P<0.001)$, and PAL $(P<0.001)$ in
2009 than 1 decade earlier and spent less time playing outdoors $(P<0.001)$ and walking to school $(P=0.043)$. Although the prevalence of overweight and obesity was not significantly higher in 2009 than in 1999, the average BMI was significantly higher in $2009(P=0.024)$.

In 2004, Tudor-Locke et al. [23] recommended 15,000 and 12,000 steps per day for boys and girls, respectively. In the present study, $90.3 \%$ of boys and $82.5 \%$ of girls in 1999 reached these recommended step counts. In 2009 , the percentages of boys and girls who achieved the recommended step counts were only $15.7 \%$ and $40.8 \%$, respectively-significantly lower than the 1999 values $(P<0.001)$. The step counts in 2009 in the present study are quite similar to previous results by McCormack et al. [2] in 2007 and Nemoto et al. [4] in 2009 examination. In contrast, the step counts in 1999 in the present study were $20,832 \pm 4694$ and $16,087 \pm 4840$ for boys and girls, respectively. These values are relatively higher than previous reports by Rowlands et al. [1] in late 1990s and Kito et al. [3] in early 1980s. A possible reason for this is that the elementary school examined in the present study is located at the boundary of an urban area and serves a geographically larger school district than typical Japanese urban schools. The children had been instructed to walk to school even their house is over $2 \mathrm{~km}$ apart from school. However, the increased perception in parents for risks of accidents during walk to school only children, some parents drive their children partway recently. The decrease in the amount of time spent walking to school over the 10year study period was mostly due to an increase in the proportion of children being driven partway by parents in the morning. Previous studies have also found a decrease in active transportation to school in Switzerland [24] and the USA [25]. Reasons that have been suggested for this trend include increased distances to school and, where distances have not increased, reduced availability of bikes and increased numbers of cars per household. Additionally, increased awareness of, and anxiety about, motor vehicle accidents that may occur while walking to school in Japan may also play a role in the tendency of parents to drive their children to school.

Cooper et al. [26] reported that children who walked to school had $43 \%$ higher mean accelerometer counts per minute before school than those traveling by car. Loucaides and Jago [27] reported that children who walked to school had higher step counts during the before- and after-school period, and the whole day, in comparison to children who used motorized transport. It has been reported that rural children in Japan perform less PA, and especially spend less time walking to school, than urban children [5]. Thus, walking to school is an important factor in determining daily physical activity, and increasing the number of children who walk to school could be a major strategy for promoting childhood health. 
Tudor-Locke et al. [28] reported in 2006 that boys took significantly more total steps per day than girls, including more steps during recess, lunchtime, and afterschool. Girls took more steps than boys before school, but boys and girls took the same number of steps during structured physical education classes. Lunchtime PA represented the most important source of daily PA (15-16 \%) obtained during school hours for both boys and girls, whereas recess accounted for 8-9 \% and physical education class accounted for $8-11 \%$ of the students' total steps per day. However, almost half of the daily steps taken by schoolchildren are attributable to after-school activities. Nemoto et al. [4] reported that boys had higher step counts and PA than girls, and that this was associated with the amount of time spent playing outdoors. In the present study, we found that boys took significantly more total steps per day, and had greater TEE and PAEE, than girls. Our findings indicate that in 2009, children spent less time playing outdoors and walking to school than did the children in 1999, and the time spent playing outdoors was significantly correlated with the PA measured by the accelerometer; these findings are similar to those of previous studies. Haug et al. [29] reported that students with access to more outdoor facilities were three times more likely to be active during recess than students with access to fewer facilities. Thus, physical environment may be a factor that determines the PA of schoolchildren, and altering the environment may be one way to increase PA on a population level.

It is important to note that body composition, such as percent body fat or skeletal and muscle development, should be examined not only BMI. Scheffler, Rietsch, and their colleagues examined secular trends of height, BMI, and external skeletal robustness (Frame-Index or pelvic breadth) and the relationship between PA and BMI, percent body fat, and Frame-Index [30-34]. That means that two variables correlate with BMI-a fat content and a skeletal part. This indicates that BMI is not merely high due to a high body fat content but rather due to high skeletal part. Low physical activity can cause the reduction of external skeletal robustness, the increase of BMI and body fat. They demonstrate an association between external skeletal robustness and PA, which is not captured in BMI measurements. We found significantly but weak correlations between BMI and step counts, duration of sleeping, and bedtime. We did not examine any body composition in this study, and this is a limitation of this study.

Sigmundova et al. [35] reported that prevalence of overweight and obesity in Czech adolescents increased from $5.5 \%$ in $1998-2000$ to $10.4 \%$ in $2008-2010$, step count in weekdays, but not in weekends, significantly decreased, and self-reported walking and aerobic exercise duration decreased between those two cohorts. Sigmund et al. [36] reported similar trend of increased obesity prevalence and decreased moderate-to-vigorous intensity PA between 2002 and 2014 in Czech adolescents. Booth et al. [37] reviewed previous researches and found mixed results, and inconsistent magnitudes of change were identified when exploring trends in different contexts of physical activity for children and adolescents over the last few decades. Taken overall, organized sport participation was increased: consistent declines in active transport were found in all of seven studies investigating active transport. Because few studies investigated the secular trend of PA or step count using objective methods, they stated that need more evidence to conclude. Our finding about the secular trends of decreasing objectively measured step counts and PA in Japanese children supports the importance of PA to their healthy development. As Booth et al. [37] found from the review, consistent declines in active transport highlight this context as a suitable intervention target.

The information technology environment has changed markedly in recent years, and these changes have transformed children's play in daily life. Nelson et al. [38] reported that secular trends further indicated dramatic increases in mid-adolescent weekly computer use from 1999 to 2004; from 8.8 to $11.1 \mathrm{~h}$, and 10.4 to $15.2 \mathrm{~h}$ in girls and boys, respectively. We could not examine the effect of computer or smartphone use on children's PA in the present study, and further research is needed in this area. Another limitation of the present study was that all of the participants were from just one elementary school, and therefore, the results may not be applicable to all populations in Japan. However, the decrease in step counts that we observed is similar to that reported in adults in a recent government report [39]. In addition, we did not examine activity in weekends, organized sport participation, as well as body composition, maturational status, and height and weight growth velocity [40]. As another potential confounders, we did not examine the effect of climate and weather, or SES and education status of parents on children's PA. Further, large-scale researches are needed to examine these issues in more depth using random sampling.

\section{Conclusions}

The step counts, TEE, AEE, and PAL of Japanese urban schoolchildren were significantly lower in 2009 than 1 decade earlier in the same region. Significantly, less time was spent playing outdoors and walking to school in 2009 than was spent 1 decade ago. The average BMI was significantly higher in 2009 compared with 1999, although the prevalence of overweight and obesity was not significantly different. Physical activity was significantly 
correlated with time spent playing outdoors and walking to school. Modern children have lower physical activity levels than the children of a decade ago, and this may be at least partly a result of less time being spent playing outdoors or active transport to school.

\section{Abbreviations}

AEE: activity energy expenditure; BMI: body mass index; JIS: Japanese Industrial Standards; PA: physical activity; PAL: physical activity level; TEE: total energy expenditure

\section{Competing interests}

Non-financial competing interests.

\section{Authors' contributions}

$\mathrm{Al}, \mathrm{YY}, \mathrm{SN}$, and MK contribute to the conception and design, acquisition of data, analysis, and interpretation of data. Al and YY drafted the manuscript. $\mathrm{SN}$ and MK revised the manuscript critically. All of the authors have given final approval.

\section{Acknowledgements}

This study was supported by JSPS KAKENHI to a research grant to A.I. (21500675) and M.K. (23650408).

\section{Author details \\ 'Department of Health, Sports and Nutrition, Faculty of Health and Welfare, Kobe Women's University, 4-7-2 Minatojima Nakamachi, Chuo-ku, Kobe 650-0046, Japan. '2Department of Nutritional Science, National Institute of Health and Nutrition, 1-23-1 Toyama, Shinjuku-ku, Tokyo 162-8636, Japan. ${ }^{3}$ Department of Bioscience and Biotechnology, Faculty of Bio-environmental Science, Kyoto Gakuen University, 1-1, Nanjo-Otani, Sogabe, Kameoka, Kyoto 621-8555, Japan. ${ }^{4}$ Laboratory of Sports and Health Science, Kyoto Prefectura University of Medicine, 465 Kajii-cho, Kamigyo-ku, Kyoto 602-0841, Japan.}

Received: 11 August 2015 Accepted: 26 October 2015

Published online: 06 November 2015

\section{References}

1. Rowlands AV, Eston RG, Ingledew DK. Relationship between activity levels, aerobic fitness, and body fat in 8- to 10-yr-old children. J Appl Physiol. 1999:86(4):1428-35.

2. McCormack GR, Giles-Corti B, Timperio A, Wood G, Villanueva K. A cross-sectional study of the individual, social, and built environmental correlates of pedometer-based physical activity among elementary school children. Int J Behav Nutr Phys Act. 2011;8:30.

3. Kito N, Amano Y, Takemoto H, Yoneda Y, Yoshida T, Goya T, et al. Effect of daily physical activity on cardiorespiratory fitness in pre-school and elementary school children. Descente Sports Science. 1983;4:92-7.

4. Nemoto Y, Inayama T, Kitabatake Y, Arao T. Physical activity levels and its related factors in elementary school children. Jpn J school Health. 2011;53:329-42 [in Japanese with English abstract].

5. Itoi A, Yamada Y, Watanabe Y, Kimura M. Physical activity, energy intake, and obesity prevalence among urban and rural schoolchildren aged 11-12 years in Japan. Appl Physiol Nutr Metab. 2012;37(6):1189-99.

6. Joens-Matre RR, Welk GJ, Calabro MA, Russell DW, Nicklay E, Hensley LD. Rural-urban differences in physical activity, physical fitness, and overweight prevalence of children. J Rural Health. 2008;24(1):49-54.

7. Bassett Jr DR, Tremblay MS, Esliger DW, Copeland JL, Barnes JD, Huntington GE. Physical activity and body mass index of children in an old order Amish community. Med Sci Sports Exerc. 2007:39(3):410-5.

8. Onywera VO, Adamo KB, Sheel AW, Waudo JN, Boit MK, Tremblay M. Emerging evidence of the physical activity transition in Kenya. J Phys Act Health. 2012:9(4):554-62.

9. Uechi H, Tan N, Morita S, Kinoshita K, Takenaka K. The influence of exercise during physical education class and recess on total physical activity among elementary school children. Bulletin of the Faculty of Education, Yamaguchi University. Nat Sci. 2009:58(2):149-53.

10. Cole TJ, Bellizzi MC, Flegal KM, Dietz WH. Establishing a standard definition for child overweight and obesity worldwide: international survey. BMJ. 2000;320(7244):1240-3.
11. Kumahara H, Schutz $Y$, Ayabe $M$, Yoshioka M, Yoshitake $Y$, Shindo M, et al. The use of uniaxial accelerometry for the assessment of physical-activity-related energy expenditure: a validation study against whole-body indirect calorimetry. Br J Nutr. 2004;91(2):235-43.

12. Nakae S, Yamada Y, Kimura M, Suzuki K, Ozawa H, Hirakawa K, et al. Relations between daily energy expenditure and body fatness, physical fitness in primary school children using doubly labeled water method and accelerometer. Jpn J Phys Fitness Sports Med. 2013;62(5):353-60 [in Japanese with English abstract].

13. Yamada Y, Yokoyama K, Noriyasu R, Osaki T, Adachi T, Itoi A, et al. Light-intensity activities are important for estimating physical activity energy expenditure using uniaxial and triaxial accelerometers. Eur J Appl Physiol. 2009;105(1):141-52.

14. Abel MG, Hannon JC, Sell K, Lillie T, Conlin G, Anderson D. Validation of the Kenz Lifecorder EX and ActiGraph GT1M accelerometers for walking and running in adults. Appl Physiol Nutr Metab. 2008;33(6):1155-64.

15. Schneider PL, Crouter S, Bassett DR. Pedometer measures of free-living physical activity: comparison of 13 models. Med Sci Sports Exerc. 2004;36(2):331-5.

16. Schneider PL, Crouter SE, Lukajic O, Bassett Jr DR. Accuracy and reliability of 10 pedometers for measuring steps over a 400-m walk. Med Sci Sports Exerc. 2003:35(10):1779-84.

17. Masse LC, Fuemmeler BF, Anderson CB, Matthews CE, Trost SG, Catellier DJ, et al. Accelerometer data reduction: a comparison of four reduction algorithms on select outcome variables. Med Sci Sports Exerc. 2005;37(11 Suppl):S544-54.

18. Rafamantanantsoa HH, Ebine N, Yoshioka M, Higuchi H, Yoshitake $\mathrm{Y}$, Tanaka $\mathrm{H}$, et al. Validation of three alternative methods to measure total energy expenditure against the doubly labeled water method for older Japanese men. J Nutr Sci Vitaminol (Tokyo). 2002;48(6):517-23.

19. Nakae S, Oshima Y, Ishii K. Accuracy of spring-levered and piezo-electric pedometers in primary school Japanese children. J Physiol Anthropol. 2008;27(5):233-9.

20. Crouter SE, Schneider PL, Karabulut M, Bassett Jr DR. Validity of 10 electronic pedometers for measuring steps, distance, and energy cost. Med Sci Sports Exerc. 2003;35(8):1455-60.

21. Kumahara H, Tanaka H, Schutz Y. Are pedometers adequate instruments for assessing energy expenditure? Eur J Clin Nutr. 2009;63(12):1425-32.

22. Noda M, Saito K, Nishizawa Y, Tsushima E, Kida K, Sakano S, et al. Comparison of activity level in daily life with heart rate: Application to elderly persons of different ambulatory abilities. Environ Health Prev Med. 2006;11(5):241-9.

23. Tudor-Locke C, Pangrazi RP, Corbin CB, Rutherford WJ, Vincent SD, Raustorp A, et al. BMI-referenced standards for recommended pedometer-determined steps/day in children. Prev Med. 2004;38(6):857-64.

24. Grize L, Bringolf-Isler B, Martin E, Braun-Fahrlander C. Trend in active transportation to school among Swiss school children and its associated factors: three cross-sectional surveys 1994, 2000 and 2005. Int J Behav Nutr Phys Act. 2010;7:28.

25. McDonald NC. Active transportation to school: trends among U.S. schoolchildren, 1969-2001. Am J Prev Med. 2007:32(6):509-16.

26. Cooper AR, Page AS, Wheeler BW, Griew P, Davis L, Hillsdon M, et al. Mapping the walk to school using accelerometry combined with a global positioning system. Am J Prev Med. 2010;38(2):178-83.

27. Loucaides CA, Jago R. Differences in physical activity by gender, weight status and travel mode to school in Cypriot children. Prev Med. 2008:47(1):107-11.

28. Tudor-Locke C, Lee SM, Morgan CF, Beighle A, Pangrazi RP. Children's pedometer-determined physical activity during the segmented school day. Med Sci Sports Exerc. 2006;38(10):1732-8.

29. Haug E, Torsheim T, Sallis JF, Samdal O. The characteristics of the outdoor school environment associated with physical activity. Health Educ Res. 2010;25(2):248-56.

30. Rietsch K, Eccard JA, Scheffler C. Decreased external skeletal robustness due to reduced physical activity? Am J Hum Biol. 2013;25(3):404-10.

31. Rietsch K, Godina E, Scheffler C. Decreased external skeletal robustness in schoolchildren-a global trend? Ten year comparison of Russian and German data. PLoS One. 2013;8(7):e68195.

32. Scheffler $C$. The change of skeletal robustness of 6-12 years old children in Brandenburg (Germany)-comparison of body composition 1999-2009. Anthropol Anz. 2010;68(2):153-65.

33. Scheffler C, Gniosdorz B, Staub K, Ruhli F. Skeletal robustness and bone strength as measured by anthropometry and ultrasonography as a function of physical activity in young adults. Am J Hum Biol. 2014;26(2):215-20. 
34. Scheffler $C$, Hermanussen M. Is there an influence of modern life style on skeletal build? Am J Hum Biol. 2014;26(5):590-7.

35. Sigmundova D, El Ansari W, Sigmund E, Fromel K. Secular trends: a ten-year comparison of the amount and type of physical activity and inactivity of random samples of adolescents in the Czech Republic. BMC Public Health. 2011;11:731.

36. Sigmund E, Sigmundova D, Badura P, Kalman M, Hamrik Z, Pavelka J. Temporal Trends in Overweight and Obesity, Physical Activity and Screen Time among Czech Adolescents from 2002 to 2014: A National Health Behaviour in School-Aged Children Study. Int J Environ Res Public Health. 2015;12(9):11848-68.

37. Booth VM, Rowlands AV, Dollman J. Physical activity temporal trends among children and adolescents. J Sci Med Sport. 2015;18(4):418-25.

38. Nelson MC, Neumark-Stzainer D, Hannan PJ, Sirard JR, Story M. Longitudinal and secular trends in physical activity and sedentary behavior during adolescence. Pediatrics. 2006;118(6):e1627-34.

39. Ministry of Health, Labour and Welfare. 2011 National Health and Nutrition Survey. http://www.mhlw.go.jp/bunya/kenkou/eiyou/h23-houkoku.html

40. Nakano T, Sei M, Ewis AA, Munakata H, Onishi C, Nakahori Y. Weight and height growth velocities of Japanese boys and girls between age 7 and 14 years: a critical window for early adolescent overweight risk. J Med Invest. 2010:57(1-2):124-32

\section{Submit your next manuscript to BioMed Central and take full advantage of:}

- Convenient online submission

- Thorough peer review

- No space constraints or color figure charges

- Immediate publication on acceptance

- Inclusion in PubMed, CAS, Scopus and Google Scholar

- Research which is freely available for redistribution 